\title{
Effects of AJAX Technology on the Usability of Blogs
}

\author{
Sumonta Kasemvilas and Daniel Firpo \\ School of Information Systems and Technology, Claremont Graduate University, \\ 130 E. 9th Street, Claremont, CA 91711, USA \\ \{Sumonta.Kasemvilas, Daniel.Firpo\}@cgu.edu
}

\begin{abstract}
AJAX can enhance Web applications by updating a part of the Web page instead of the whole page. This change of technology relates to a usability issue. We used WordPress 2.3 to create two versions of blogs: non-AJAX and AJAX. Then we conducted an experiment by giving a task scenario to eight participants. We collected performance data by recording users' mouse movements during the experiment and collected preference data by providing a questionnaire after the tasks. Finally, we conducted post-experiment interviews to gather participants' experiences. The quantitative results show that AJAX did not improve users' performances the first time they used it, while qualitative interviews demonstrate participants' satisfaction with AJAX blogs.
\end{abstract}

Keywords: AJAX, Blog, Ease of Learning, Efficiency of Use, Error Frequency and Severity, Experiment, Satisfaction, Usability, WordPress.

\section{Introduction}

AJAX (Asynchronous JavaScript and XML) is a set of technologies such as eXtensible Markup Language (XML), XMLHttpRequest, Cascading StyleSheets (CSS), and the Document Object Model (DOM), combined with JavaScript. It is not a single technology, but several technologies that, when used together, enhance the capability of Web applications in innovative ways [1]. Many corporations use AJAX in applications, such as Google Maps, Gmail, iGoogle, Hotmail, and Yahoo Flickr.

An advantage of AJAX is that Web browsers do not need to refresh the whole page. They only need to reload a portion of the page, which makes the Web site load faster and increases performance, because users can receive responses from the server faster than in classical Web applications. However, this also leads to a problem with AJAX. Users who are familiar with old-style Web applications may not be able to effectively use Web applications that contain AJAX technology due to a lack of understanding of how AJAX works. The users may not notice what has changed on the screen, or they might be waiting for the results to display, or for a response from the browser. Users might need to get accustomed to new conventions. This change of technology relates to a usability issue [2].

Blogs, a slang form of the term "Web logs," are a Web 2.0 technology used extensively on the World Wide Web. Blogging has gained quite a bit of popularity in the recent years. "Blog" was named as the "word of the year" in 2004 by MerriamWebster. The large increase in popularity of blogs has led to the rapid growth in the 
number of blog users, from individuals using them for personal use, to larger entities such as companies or universities. Blogs play a vital role not only in businesses and organizations, but also in academia. For example, the Brisbane Graduate School of Business at Queensland University of Technology records students' experiences through the use of the 'MBA blog' [3]. Thus, it is in our interest to study human computer interaction of AJAX technology in blogs.

\section{AJAX}

Classical Web applications use HTTP protocol to give requests to and receive responses from the server. This process takes time and refreshes the user's whole screen, and a sign such as a rotating globe, a spinner, or a progress bar shows the user that the browser is loading. However, now we have moved on to a JavaScript-based paradigm, which calls an AJAX engine to send asynchronous HTTP requests to the server.

AJAX supposedly improves the effectiveness of the Web by updating a part of the Web page instead of the whole page. It seamlessly exchanges small quantities of data between the browser client and the server. Because refreshing the Web page is not required when updating, the page becomes more interactive. This results in higher responsiveness, speed, and functionality [2].

AJAX is a client-side technology. In the AJAX Web application model, instead of sending an HTTP request from client to server as before, the user interface of the browser client will send a JavaScript call to the AJAX engine. Then, the AJAX engine sends an asynchronous HTTP request to the Web and/or XML servers. From the server side to the client side, the server sends XML data to the AJAX engine, and the AJAX engine sends HTML and CSS data to the user interface of the client. This also decreases bandwidth usage when compared to classical Web applications. AJAX also gains the advantage of JavaScript, in which developers only need to code once, and their code can work across different platforms. This makes AJAX more adaptable.

However, AJAX has several disadvantages. Because it does not require a whole page reload, users cannot push the back button to go back to a prior state. This can cause problems because most users become accustomed to this behavior when they use Web browsers. Moreover, users cannot add bookmarks to keep a certain stage of the page when the page dynamically updates only small portions on the screen [4]. These problems may be solved by adding more complicated programming.

Recently, Kluge, Kargl, and Weber [5] reported on the effects of AJAX technology on usability in Web applications such as message boards and auto-completion widgets, while our study focuses specifically on blogs. They studied only user satisfaction and time for completion of tasks. They looked at time for completion of tasks as a parameter of efficiency of use. They concluded that AJAX technology dramatically improves users' satisfactions and efficiency of use in some scenarios. However, our study not only focuses on efficiency of use and satisfaction, as in Kluge et al's [5] study, but also on other measures of usability, such as ease of learning and error frequency and severity, which were not measured in their study. 


\section{Research Question and Hypotheses Development}

Krug [6] asserts that one of the most important factors for Web usability is when users glimpse the Web page and are capable of easily interacting with it. Users should not have to take a long time to think about how to use the Web page. Oulasvirta and Salovaara [7] assert that it is important for a user interface to be invisible, as an interface must be uncomplicated (requiring no other knowledge besides the common sense of the user to operate) and interactive (ready to respond to the user on a continuous basis).

Usability relates to the ability of users to learn and utilize a system or a product, such as a Web site or a computer application, to accomplish their purposes [8]. It includes the degree of satisfaction they perceive from learning and using the system [8]. Measurement of usability involves a group of factors that we need to consider for a user interface [8], [9]. First, ease of learning is measured from the ability of users who have never seen the user interface before to easily accomplish simple tasks without substantial training [8], [9], [10]. This includes effectiveness or the ability of users to successfully achieve tasks. Second, efficiency of use refers to how quickly users who have used the system before can complete their tasks easily and without frustration [8], [9], [10]. Third, memorability refers to how easily users can capably use the system again after not using the system for a period of time [8], [9]. Fourth, error frequency and severity refers to how often users make mistakes when using the system, the severity of these mistakes, and how easily they can recover from these mistakes [8], [9]. Finally, participative satisfaction refers to the extent to which users are satisfied with the system [8], [9], [10].

Currently, few studies have been conducted on the relationship between AJAX technology and Web usability when users utilize blogs. We are interested in finding out if AJAX technology within a blog leads to improvements in Web usability. We will examine whether adding AJAX plugins to a blog has a positive effect on the usability of that blog.

To measure if AJAX technology affects the usability of a blog, we categorize these factors into two groups: preference and performance [10]. First, preference is measured from participative satisfaction. Second, performance is measured from ease of learning, error frequency and severity, as well as efficiency of use. We did not measure memorability because the experiment was done in one session. In addition, Kluge et al. [5] concluded that user satisfaction and efficiency of use when using AJAX technology are higher than when not using AJAX. Thus, we hypothesize that:

HYPOTHESIS 1: The usability of blogs with AJAX technology is greater than in regular blogs. blogs.

$\mathrm{H}_{1 \mathrm{a}}$ : The ease of learning in blogs using AJAX technology is greater than in regular

$\mathrm{H}_{1 \mathrm{~b}}$ : The error frequency and severity in blogs using AJAX technology is lower than in regular blogs.

$\mathrm{H}_{1 \mathrm{c}}$ : The participation satisfaction of users using blogs with AJAX technology is greater than the participation satisfaction of users using regular blogs.

HYPOTHESIS 2: The efficiency of use in blogs using AJAX technology is high when users have used AJAX-enhanced blogs before. 


\section{Experiment Design}

\subsection{System Design}

To test Web usability, we created two versions of a blog that had similar interfaces. The first version did not have AJAX plugins, but the second version did. We used WordPress $2.3^{1}$ to create blogs in this study. WordPress is a well-known blog application that provides easy installation and usage. Calendar, search box, and comment are basic functions of blogs in WordPress. One can find these functions in most WordPress blogs. This makes it easier to compare the usability of regular blogs and blogs using AJAX technology. In this study, we installed three AJAX plugins.

First, AJAX Calendar ${ }^{2}$ was used to find articles for each day and month. This plugin allows the reader to click a special button to show all articles in a specific month, a service which the regular calendar does not offer. When the user clicks that button, AJAX will retrieve all articles in that particular month and display them on the bottom of the calendar. This plugin makes AJAX blogs faster than their non-AJAX counterpart, since it refreshes only this specific part of the page.

Second, LiveSearch ${ }^{3}$ allowed users to search articles within the blog. This plugin shows the results in a pop-up style menu using AJAX technology (similar to how in Google Suggest, as users type each character, the software displays a set of words that relates to these characters to predict what the user is searching for).

Finally, Inline AJAX Comment ${ }^{4}$ allowed users to add comments and auto-update those comments without a full page reload. With AJAX technology, this plugin provides a much smoother, faster commenting feature in the blog. Users can also click to Show or Hide comments.

\subsection{Task Scenario}

A task scenario was designed for readers because most people use blogs in their daily lives to find information about specific interests and participate with other users. The set of tasks is a basic operation readers perform when they visit a blog. The readers will find interesting articles, read them, search for related information, and add comments.

In AJAX version, participants complete a set of tasks by using plugins that contain AJAX technology, while in non-AJAX version, participants use the default plugins that come with the original version of WordPress. To test Web usability, participants needed to accomplish a set of tasks that was listed on the instruction sheet. First, participants needed to login as guests. Second, they needed to use the calendar in the left sidebar to find an article named "Blog\#2" in September, and post a comment on that article. Third, before writing any comments, participants needed to use the search box in the left sidebar, input the word "dog," and find the article related to this word. Then, they had to copy the paragraph from the article to add in a comment box of the blog's article. They needed to do the same set of tasks in both non-AJAX and AJAX

\footnotetext{
${ }^{1} \mathrm{http} / / /$ codex.wordpress.org/Version_2.3

${ }^{2} \mathrm{http} / / /$ wordpress.org/extend/plugins/ajax-calendar/

${ }^{3} \mathrm{http}: / /$ wordpress.org/extend/plugins/livesearch/

${ }^{4}$ http://www.ditii.com/2006/07/07/wordpress-plugin-inline-ajax-comments/
} 
versions. Then, they used an AJAX version one more time at the end of the experiment so we could measure efficiency of use.

\subsection{Method and Procedure}

To identify usability problems, our experiment was conducted on a small group of users as per Nielsen's suggestion [9]. Nielsen [11] claimed that "[t]he best results come from testing no more than 5 users and running as many small tests as you can afford." More test subjects would only result in a marginal increase in the number of problems, errors, and different completion times for tasks found [11]. Moreover, the small number of participants for qualitative usability testing is enough [9].

We recruited eight participants for this study. All users had to complete all three experiments (non-AJAX, AJAX for the first time, and AJAX for the second time) within the same day, back to back to back. To decrease participant bias and avoid an order effect resulting from the participants' expectations and impressions for the next version of the blog after completing the first one, we used counterbalanced design. Half the participants used the non-AJAX version first, then did the same tasks again with AJAX version, while the other half used the AJAX version before the non-AJAX version. After all eight participants finished the set of tasks with these two versions (AJAX and non-AJAX), we asked them to repeat the set of tasks with the AJAX version to measure efficiency of use. We measured whether they improved performance efficiently after they learned how to use the new kind of blog that incorporated AJAX technology the first time around [12].

At the end of the experiment, participants were asked to complete questionnaires about their background, blog experience, and questions about satisfaction with the blogs. After participants finished answering the questionnaire, we conducted postexperiment interviews to collect qualitative data to substantiate quantitative results.

\subsection{Usability Measurement}

In the usability test, we collected quantitative data of both participants' performance and participants' preference (Table 1). We collected two types of data: what really happened when participants used the blog (performance data) and what participants thought when they used it (preference data) [10].

For the performance metric, we used the free trial software All In One Keylogger ${ }^{5}$ for Windows. This software can visually capture users' mouse movements and to be reported in visual logs and HTML reports. It records where users click on the screen, how they move the mouse, and when they perform certain actions. We used this information to calculate a performance metric for the usability test. To prevent threats to validity, this software has a "hidden mode" feature. Participants were not aware that the researcher observed their movements when they used the blog.

For user preference, we used a questionnaire to measure how satisfied the users were when using the blog. In the questionnaire, ratings on a 1 to 5 Likert scale were used to allow for variation in data. For example, to find out to what extent participants prefer any version, the participants could express their feelings from 'strongly disagree' (1) to 'strongly agree' (5).

\footnotetext{
${ }^{5}$ http://www.relytec.com/download.htm
} 
Table 1. Usability metric (Adapted from [10])

\begin{tabular}{|c|c|}
\hline Performance Usability Metric & Usability Measure \\
\hline $\begin{array}{l}\text { Total time to completion } \\
\text { (Time) }\end{array}$ & $\begin{array}{l}\text { Ease of learning: } \\
\text { - Can participants complete the task scenario quickly? }\end{array}$ \\
\hline Number of steps (Step) & $\begin{array}{l}\text { Ease of learning: } \\
\text { - How many steps do participants take in order to } \\
\text { successfully complete the tasks? }\end{array}$ \\
\hline Amount of confusion & Error frequency and severity: \\
\hline (Confusion) & - How many times do participants get confused? \\
\hline $\begin{array}{l}\text { Pathway analysis and the } \\
\text { number of user errors (Error) }\end{array}$ & $\begin{array}{l}\text { Error frequency and severity: } \\
\text { - How many errors do participants make when they use the } \\
\text { blog? }\end{array}$ \\
\hline Preference Usability Metric & Usability Measure \\
\hline User satisfaction & $\begin{array}{l}\text { Participative satisfaction: } \\
\text { - Do participants get pleasure from using the blog? }\end{array}$ \\
\hline User comments & $\begin{array}{l}\text { Participative satisfaction: } \\
\text { - Are participants confused when they use the blog? }\end{array}$ \\
\hline Preference ratings & $\begin{array}{l}\text { Participative satisfaction: } \\
\text { - Do participants prefer the design of the blog? }\end{array}$ \\
\hline
\end{tabular}

\section{Results}

\subsection{Data Analysis}

The participants were eight graduate students aged between 20-40 years old. Three of them were male and the other five were female. All participants were familiar with using the Internet, and half of them had their own blogs. In hypothesis $\mathrm{H}_{1 \mathrm{a}}$, we were interested in whether the ease of learning in blogs using AJAX technology is greater than in regular blogs. $\mathrm{H}_{1 \mathrm{a}}$ was tested by paired sample t-test on Time and Step parameters of participants using non-AJAX blogs and AJAX blogs for the first time (Table 2). The results indicated that the presence of AJAX increases the time needed to complete tasks for first-time users. At the significant level of .05 (1-tailed), users spent significantly more time completing tasks in AJAX blogs than in regular blogs. However, number of steps participants took to complete tasks in AJAX and nonAJAX blogs were not significantly different. Thus, $\mathrm{H}_{1 \mathrm{a}}$ was disconfirmed.

In hypothesis $\mathrm{H}_{1 \mathrm{~b}}$, we were interested in whether or not the error frequency and severity in blogs using AJAX technology was lower than in regular blogs. To test $\mathrm{H}_{1 \mathrm{~b}}$, paired sample t-test was performed on the participants' Confusion and Error parameters when they used non-AJAX blogs and AJAX blogs for the first time (Table 2). At the significant level of .05 (1-tailed), contrary to our hypothesis, users had more confusion and errors in AJAX blogs than in regular blogs. Thus, $\mathrm{H}_{1 \mathrm{~b}}$ was also disconfirmed.

In hypothesis $\mathrm{H}_{1 \mathrm{c}}$, we were interested in whether the participation satisfaction of users when they used blogs with AJAX technology was greater than their participation satisfaction when they used regular blogs. We calculated mean and standard deviation to examine whether the average preference of users when using non-AJAX blogs was different from when they used AJAX blogs. We tested the hypothesis $\mathrm{H}_{1 \mathrm{c}}$ by using paired sample t-test of preference between the two versions 
Table 2. Difference of performance scores between AJAX for the first time (AJAX1) and NON-AJAX

\begin{tabular}{|c|c|c|c|c|c|c|}
\hline \multirow{2}{*}{$\begin{array}{l}\text { Usability Dimension } \\
(N=8)\end{array}$} & \multicolumn{2}{|c|}{ AJAX1 } & \multicolumn{2}{|c|}{ NON-AJAX } & \multirow[b]{2}{*}{$t$} & \multirow[b]{2}{*}{$p$} \\
\hline & $M$ & $S D$ & $M$ & $S D$ & & \\
\hline Time & 455.88 & 144.21 & 322.13 & 109.90 & 2.01 & .042 \\
\hline Step & 13.13 & 4.36 & 14.75 & 3.92 & -0.60 & .284 \\
\hline Confusion & 6.25 & 5.31 & 1.50 & 2.73 & 1.91 & .049 \\
\hline Error & 4.50 & 5.10 & 0.50 & 0.76 & 2.11 & .037 \\
\hline
\end{tabular}

Table 3. Difference of preference scores between AJAX and NON-AJAX

\begin{tabular}{|c|c|c|c|c|c|c|}
\hline \multirow{2}{*}{$\begin{array}{l}\text { Usability Dimension } \\
(N=8)\end{array}$} & \multicolumn{2}{|c|}{ AJAX } & \multicolumn{2}{|c|}{ NON-AJAX } & \multirow{2}{*}{$t$} & \multirow{2}{*}{$p$} \\
\hline & $M$ & $S D$ & $M$ & $S D$ & & \\
\hline Satisfaction & 3.58 & 0.97 & 3.13 & 0.56 & 0.89 & .201 \\
\hline
\end{tabular}

Table 4. Difference of performance scores between AJAX for the first time (AJAX1) and AJAX for the second time (AJAX2)

\begin{tabular}{|c|c|c|c|c|c|c|}
\hline \multirow{2}{*}{$\begin{array}{l}\text { Usability Dimension } \\
(N=8)\end{array}$} & \multicolumn{2}{|c|}{ AJAX1 } & \multicolumn{2}{|c|}{ AJAX2 } & \multirow{2}{*}{$t$} & \multirow{2}{*}{$p$} \\
\hline & $M$ & $S D$ & $M$ & $S D$ & & \\
\hline Time & 455.88 & 144.21 & 176.13 & 86.63 & 5.87 & .000 \\
\hline Step & 13.13 & 4.36 & 9.13 & 1.25 & 2.50 & .021 \\
\hline Confusion & 6.25 & 5.31 & 0.13 & 0.35 & 3.20 & .008 \\
\hline Error & 4.50 & 5.10 & 0.00 & 0.00 & 2.50 & .021 \\
\hline
\end{tabular}

of blogs, non-AJAX and AJAX (Table 3). The results indicated that, at the significant level of .05 (1-tailed), users' satisfaction with AJAX blogs was not greater than their satisfaction with regular blogs. Thus, $\mathrm{H}_{1 \mathrm{c}}$ was not supported.

In hypothesis $\mathrm{H}_{2}$, we were interested in whether the efficiency of use in blogs using AJAX technology is high when users have used AJAX-enhanced blogs before. Thus, $\mathrm{H}_{2}$ was tested by paired sample t-test on participants' Time, Step, Confusion, and Error parameters when they used AJAX for the first time and when they used it again for the second time (Table 4). At the significant level of .05 (1-tailed), users spent less time, took fewer steps, with less confusions and errors in AJAX blogs the second time around. Thus, $\mathrm{H}_{2}$ was confirmed.

From the data, participants using AJAX for the first time took more time to finish the task (Figure 1), felt more confused, and made more errors compared to when they did the same set of tasks without AJAX. Therefore, $\mathrm{H}_{1}$ was disconfirmed. However, in $\mathrm{H}_{2}$ when using the AJAX version for the second time, participants spent less time (Figure 1), used fewer links, were less confused, and made slightly fewer errors than when they performed the set of tasks without AJAX. Thus, the data supports $\mathrm{H}_{2}$. This indicates that learning is a very important step for introducing a new technology. 


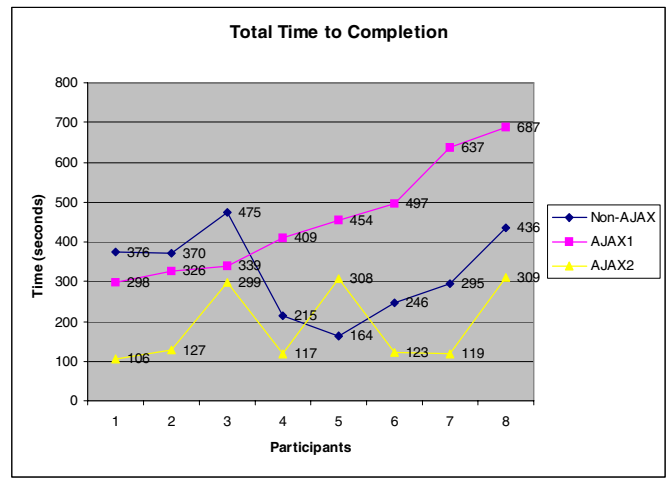

Fig. 1. This graph shows the time to completion of each participant when each participant used Non-AJAX blogs, AJAX blogs for the first time, and AJAX blogs for the second time. Three participants out of eight spent less time when they used the AJAX version for the first time as compared with the non-AJAX version. Seven out of eight spent less time on the AJAX version the second time as compared with the non-AJAX version. All participants spent less time when they used the AJAX version for the second time as compared with the first time.

\subsection{Post-experiment Interview}

Although the number of participants was not large, which may cause the power of the statistical test to be low, the results of most statistical analyses reached significant level of alpha .05. However, most of the results surprisingly stand in direct contrast to our hypothesis. Thus, we would like to triangulate the results using both quantitative and qualitative methods.

We conducted post-experiment interviews to collect impression of participants when they used two versions of blogs and to see whether their satisfaction matched their performance when they worked with the blogging software. Some sample questions were asked such as: Were you confused when you used the AJAX blog for the first time? Why? If you prefer the AJAX blog to the non-AJAX blog, please give your reasons why.

In the study, we had eight participants, and two of them did not like the AJAX version because the interface was more complicated than a non-AJAX version. One participant explained that

I prefer non-AJAX version especially if I know exactly what I am searching for. $A J A X$ version confuses my usage. In general, I prefer simplicity rather than sophistication when I search any web browsers.

Another participant said:

I don't like it because it is too complicated. It is not necessary.

The rest of the participants liked the AJAX version because it provided functions that help users do their jobs faster and more interactively. The following comments point out the potential benefits of AJAX version: 
It's much easier to find what I want using calendar and search box. I like search box the most due to the ease of use. It works like Google Suggest. The interface is much better than non-AJAX version.

The AJAX blog has functions that help users do their jobs faster.

I love the search box. AJAX blog has more functions and takes less time to refresh.

It's more useful when one knows how it works.

AJAX should have increased usability performance and preference, and while the interviews showed that most of the participants liked AJAX, the statistical results did not support our first hypothesis. This may be because some of the AJAX-specific features were confusing for them when compared with regular blogs. Participants expressed that when they used the AJAX blog, they felt confused with issues such as how AJAX Calendar only changes a small portion of the screen. They did not understand how it worked and found it difficult to use when compared with the nonAJAX version. This may be explained with the need for time to get used to new technology. Participants' performances were low when they used the AJAX blog for the first time, and they confessed that they had not knowingly used AJAX technology before. Thus, they felt unfamiliar with the new interface conventions. However, the participants' performance when they used AJAX for the second time showed that after the users learned and understood how to use AJAX technology, their performance improved significantly.

\section{Discussion and Conclusion}

This study attempts to measure how AJAX technology affects Web usability when users use a blog. We designed two versions of a blog, which have a similar user interface. However, WordPress provides many different theme styles. Thus, a theme chosen in this study may not have the same result as if we had used other themes. The experiment was controlled in a closed environment to record users' mouse movements but it still depended on the speed of the Internet and CPU of the computer used during the experiment. This may cause delay times or load times that do not relate to user performance.

Kluge et al's [5] study shows that AJAX technology increases efficiency of use and satisfaction in AJAX Web application in some task scenarios, but our study showed that AJAX technology does not always increase usability. This may point out that learning for new technology is vital, especially when users are familiar with traditional technology.

In the United States, the National Institute of Standards and Technology (NIST) has begun to address some of the AJAX technology issues in the need for Web administrators and IT Management to monitor usability and security of Webcode design, development, test, and maintenance [13]. Blogs are a prevalent Web 2.0 tool that has been widely adopted amongst a broad subset of society, including many users who are not particularly tech savvy. To us, it is important to investigate what happens when one applies new technology to a tool so we can learn how to improve the technology and enhance human computer interaction. From our results, we can see 
that although in an easy-to-use tool with widespread adoption, such as blogs, there are many challenges to overcome in applying new technology that users are not familiar with. From this perspective, the results of this paper suggest the problems of using AJAX technology in a blog and may help Web developers use AJAX technology to improve Web usability of a blog.

\section{References}

1. Garrett, J.J.: Ajax: A New Approach to Web Applications, http: / /www . adaptivepath.com/ideas/essays / archives / 000385 .php

2. Paulson, L.D.: Building Rich Web Applications with Ajax. Computer, 14-17 (2005)

3. Williams, J.B., Jacobs, J.: Exploring the Use of Blogs as Learning Spaces in the Higher Education Sector. Australasian Journal of Educational Technology 20(2), 232-247 (2004)

4. West, J.: Ajax: not just another acronym or is it? Searcher 14, 13-15 (2006)

5. Kluge, J., Kargl, F., Weber, M.: The Effects of the AJAX Technology on Web Application Usability. In: WEBIST 2007 International Conference on Web Information Systems and Technologies, pp. 289-294 (2007)

6. Krug, S.: Don't Make Me Think: A Common Sense Approach to Web Usability. New Riders Press, New York (2000)

7. Oulasvirta, A., Salovaara, A.: A Cognitive Meta-analysis of Design Approaches to Interruptions in Intelligent Environments. In: Conference on Human Factors in Computing Systems, pp. 1155-1158. ACM, New York (2004)

8. Usability gov., http://www.usability.gov/basics/whatusa.html

9. Jakob Nielsen's Alertbox: Usability 101: Introduction to Usability, http: //www.useit.com/alertbox/20030825.html

10. Usability gov., http://www. usability.gov/basics/measured.html

11. Jakob Nielsen's Alertbox: Why You Only Need to Test With 5 Users, March 19 (2000), http://www.useit.com/alertbox/20000319.html

12. Nielsen, J.: Usability Engineering. Morgan Kaufmann, San Francisco (1993)

13. National Institute of Standards and Technology, http://csrc.nist.gov/publications/nistpubs/800-28-ver2/ SP $800-28 \mathrm{v} 2 \cdot \mathrm{pdf}$ 